\title{
Sleep Patterns and Their Association with Blood Pressure and Heart Rate Variability Parameters in Young Saudi Females
}

\author{
"Farrukh Majeed, ${ }^{1}$ Rabia Latif, ${ }^{1}$ Aamna Latif, ${ }^{2}$ Rehma Bibi ${ }^{3}$
}

\begin{abstract}
Objectives: Disturbed sleep patterns might alter the autonomic tone and lead to various cardiovascular morbidities. This study aimed to determine sleep patterns (quality, duration, efficiency and daytime sleepiness) and explore their association with blood pressure (BP) and heart rate variability (HRV) in apparently healthy, young Saudi females. Methods: This cross-sectional study was conducted in the Department of Physiology, Imam Abdulrahman Bin Faisal University, Saudi Arabia between March 2019 and December 2019. Self-reported Pittsburgh Sleep Quality Index and Epworth Sleepiness Scale questionnaires were used to collect data. In addition, the participants' BP and HRV was measured. Based on the cut-off values of sleep quality, duration, efficiency and daytime sleepiness scores, participants were categorised into groups. HRV and BP were compared between the groups by a t-test/one-way ANOVA. Results: A total of 98 participants were included in this study (response rate: 72.6\%). Poor sleep patterns (quality, duration and efficiency) were observed, but no association was found with BP and HRV parameters among groups with different sleep quality, duration and efficiency. Systolic BP was significantly increased in the moderate to severe daytime sleepiness group $(P=0.039)$. Dozing off as a passenger in a car, in the afternoon and after lunch were negatively correlated with HRV parameters $(\mathrm{P}<0.05)$. Conclusion: Sleep quality, duration and efficiency were not found to be statistically significant, but various dozing-off situations were associated with fluctuations in HRV parameters. Daytime sleepiness may augment sympathetic responses in apparently healthy female participants.
\end{abstract}

Keywords: Sleep; Daytime Sleepiness; Blood Pressure; Autonomic Nervous System; Sleeping Habits; Sleepiness; Saudi Arabia.

AdVANCES IN KNOWLEDGE

The current study provides a platform for education on students' sleep health.

To the best of the authors' knowledge, this is the first study to report altered blood pressure and heart rate variability parameters in young, apparently healthy female students with daytime sleepiness and in dozing-off situations.

\section{Application to Patient Care}

Disturbed sleep patterns and daytime sleepiness alters the autonomic tone and may lead to various cardiovascular morbidities, affecting health and academic performance.

The results of this study raise awareness regarding the potentially harmful effects of disturbed sleep patterns on health.

S LEEP IS A NATURAL, CALMing MECHANiSM OF all bodies and its alteration produces multiple deleterious effects such as disturbed cognition and behaviour, mental stress and chronic fatigue. ${ }^{1}$ Changes in sleep patterns might alter the autonomic tone and lead to various cardiovascular morbidities. Short sleep duration and poor sleep quality both have been associated with numerous cardiovascular disease (CVD) risk factors such as hypertension, diabetes, obesity, coronary artery diseases and myocardial infarction. ${ }^{2}$ Young adults (20-25 years old) are recommended to have at least six hours of sleep per day. ${ }^{3}$ Women are more likely than men to report poor sleep quality, long sleep latency, short sleep duration and daytime somnolence. This not only affects their quality of life but also leads to associated morbidities. ${ }^{4,5}$
University students have reported at least twice as many sleep difficulties as the general population. ${ }^{6}$ According to a study from King Khalid University (KKU) in Saudi Arabia, medical students have poor sleep quality, longer sleep latency, shorter sleep duration and the majority go to sleep after midnight. ${ }^{\text {? }}$ Gender differences have also been reported in sleep quality and other sleep variables among the student population. Female students have longer sleep latency, more awakenings and poorer sleep quality than male students. ${ }^{8,9}$

Many instruments have been developed to measure sleep quality, sleep patterns and daytime sleepiness. Two of the most widely used instruments are the Pittsburgh Sleep Quality Index (PSQI) and the Epworth Sleepiness Scale (ESS). The PSQI is a 19- 
item self-reported questionnaire designed to measure subjective sleep quality and sleep disturbances over a one-month period. These 19 items produce a global sleep quality score. Global PSQI scores greater than five are consistent with clinically disturbed or poor sleep quality. The ESS assesses the participant's daytime sleepiness. It consists of eight items of daily routine (e.g. sitting and reading, watching $\mathrm{TV}$, etc.) in which participants most likely doze off. These items are answered using a 4-point Likert scale ranging from 0 (never doze off) to 3 (high chance of dozing). ${ }^{10,11}$

Poor sleep quality was significantly associated with elevated levels of stress. Previous studies confirm that augmented stress response is always associated with sympathetic stimulation. ${ }^{12}$ The precise involvement of autonomic modulation in sleep-deprived participants is still debatable. A sympathetic predominance was observed in participants with acute sleep deficiency. ${ }^{13}$ Contrarily, an increased parasympathetic tone was also observed after sleep deprivation. ${ }^{14}$

Heart rate variability (HRV) is a non-invasive technique to measure autonomic modulation in various basic and clinical setups. ${ }^{15}$ The electrocardiograph (ECG) record can be used to measure both the time domain and the frequency domain parameters of HRV. In the time-domain analysis, average heart rate and mean of the normal-to-normal heartbeats (NN) reveal total HRV. The standard deviation of the normal-to-normal heartbeats (SDNN) indicates autonomic effects, while the square root of the mean squared differences of successive $\mathrm{NN}$ intervals (RMSSD) reveals the parasympathetic influence of the autonomic system and HRV. In the frequency-domain analysis, low-frequency power (LF) is an indicator of sympathetic activity whereas high-frequency power (HF) reflects parasympathetic (vagal) activity. The ratio of LF/HF reflects sympathovagal balance (i.e. a larger $\mathrm{LF} / \mathrm{HF}$ ratio indicates a predominance of sympathetic activity over vagal control of the heart). ${ }^{16}$

Despite innumerable research on autonomic modulation and CVD, there is a lack of studies that identify the segment of the autonomic nervous system modulated by sleep quality, sleep duration, sleeps efficiency and chances of dozing off, particularly in young, apparently healthy individuals. The purpose of the present study was to determine sleep patterns (sleep quality, duration, efficiency and daytime sleepiness) in young female students through validated questionnaires and to explore any association/correlation of BP and HRV parameters with sleep patterns. The authors hypothesised that the HRV and the BP will differ significantly in participants having poor vs normal sleep quality, short vs normal sleep duration, low vs normal sleep efficiency and normal vs moderate-severe daytime sleepiness; these sleep variables will be associated/ correlated to the BP and HRV.

\section{Methods}

A cross-sectional study was conducted between March 2019 and December 2019 at the Department of Physiology, Imam Abdulrahman Bin Faisal University, Saudi Arabia. Healthy female students from the university aged $18-22$ years were included. Those who had a past or present history of any chronic medical or psychological conditions, smoking, pregnancy and menstruating either on the day of the experiment or one week before it, were excluded. Furthermore, students who had a regular consumption of diet supplements, medications such as birth control pills and caffeine intake of more than three cups/day were excluded. Additionally, trained athletes or regularly exercising participants were also excluded.

Study's participants were invited through an advertisement in a WhatsApp (Facebook Inc., Menlo Park, California, USA) group for the university students. Raosoft ${ }^{\circledR}$ software (Raosoft, Inc., Seattle, Washington, USA) was used to calculate the sample size. Keeping the margin of error as $5 \%$ and the confidence interval as $95 \%$, a population size of 200 students (female medical students registered in year 1 and year 2 in the 2019-2020 academic year) with a response distribution of $50 \%$ resulted in a recommended sample size of 132 .

Participants were instructed to fast for 12 hours before their allotted time. To avoid any confounding factors, the body mass index (BMI; weight in kilogram/height in meter squared) was first measured. Participants who had a BMI of more than $24.9 \mathrm{~kg} / \mathrm{m}^{2}$ were excluded as high BMI is related to the higher sympathetic and lower parasympathetic activity of the heart. $^{17}$

On experiment day (i.e. the allotted day for ECG and blood pressure measurement of the participants), three ECG electrodes were used: one on each wrist around the radial artery and one on the left foot. These electrodes were connected through the ECG box to a dual bio amplifier and a PowerLab (ADInstruments ${ }^{\circledR}$, Australia). The PowerLab settings (as suggested by the manufacturer for HRV recording from ECG signals) were set at a range of $10-20 \mathrm{mV}$, sampling rate of $400-1 \mathrm{kHz}$, high pass filter of $0.3 \mathrm{~Hz}$ (to minimise iso-electric artifacts) and low pass filter of $\leq 25-50 \%$ sampling rate (typically $200-1 \mathrm{kHz}$ low-pass). ${ }^{18}$

A Finometer ${ }^{\circledR}$ cuff (FMS, the Netherlands) was placed on the middle phalanx of a middle finger to obtain continuous finger arterial BP, i.e. systolic blood pressure (SBP), diastolic blood pressure (DBP), mean 
Table 1: Characteristics of apparently healthy female Saudi Arabian students included in the current study $(\mathrm{n}=98)$

\begin{tabular}{lc} 
Characteristic & Mean \pm SD \\
Age in years & $20.4 \pm 0.5$ \\
BMI in kg/m ${ }^{2}$ & $22.1 \pm 2.4$ \\
Blood pressure parameters using Finometer & \\
Systolic blood pressure in mmHg & $122.6 \pm 11.9$ \\
Diastolic blood pressure in mmHg & $67.1 \pm 8.0$ \\
Pulse pressure in mmHg & $55.5 \pm 8.9$ \\
Arterial blood pressure in mmHg & $85.6 \pm 8.5$ \\
Heart rate variability parameters using ECG & \\
Avg rate in beats/minute & $80.5 \pm 8.9$ \\
NN mean in milliseconds & $736.2 \pm 111.3$ \\
SDNN in milliseconds & $62.4 \pm 18.8$ \\
RMSSD in milliseconds & $55.7 \pm 25.8$ \\
LF/HF & $1.43 \pm 1.02$ \\
LF in normalised units & $50.6 \pm 15.6$ \\
HF in normalised units & $43.5 \pm 13.1$ \\
Sleep-related characteristics & \\
Bed time using 24-hour clock & $13.8 \pm 10.7$ \\
Fall sleep in minutes & $23.4 \pm 15.6$ \\
Time morning wakeup in AM \pm hour & $6.1 \pm 1.2$ \\
Sleep duration in hours & $5.8 \pm 1.6$ \\
Time in bed in hours & $6.4 \pm 2.1$ \\
Eittsburgh Sleep Quality Index score & $8.2 \pm 4.0$ \\
Epworth Sleepiness Scale score & \\
\hline
\end{tabular}

$S D=$ standard deviation $; B M I=$ body mass index $E C G=$ electrocardiograph; NN mean = mean of the normal-to-normal heart beats; SDNN = standard deviation of the normal-to-normal heartbeats; RMSSD = square root of the mean squared differences of successive NN intervals; $L F=$ low frequency power; $H F=$ high frequency power.

arterial blood pressure (MABP) and the pulse pressure were calculated afterwords. ${ }^{19}$ Calibration was done after proper placement of the finger BP sensor and ECG leads.

After five minutes of stabilisation, a 5-minute ECG recording was done in the supine position for HRV, based on the European Society task force recommendation. ${ }^{20}$ From the ECG record, LabChart ${ }^{\circledR}$ software (ADInstruments ${ }^{\circledR}$, Australia) was used to derive both time-domain and frequency-domain parameters of HRV. ${ }^{20}$

To assess sleep patterns, the following sleep variables were determined: (1) sleep quality; (2) sleep duration; and (3) sleep efficiency. Sleep quality was assessed using the PSQI. In this 19-item questionnaire, the first four items inquire about bedtimes, wake times,
Table 2: Comparison of blood pressure and heart rate variability parameters between participants having normal or poor sleep quality

$\begin{array}{ccc}\begin{array}{c}\text { Sleep } \\ \text { quality } \\ \text { status }\end{array} & \text { Mean } \pm \text { SD } & P \\ \text { value }^{+}\end{array}$

Blood pressure parameters using Finometer

$\begin{array}{lccc}\begin{array}{l}\text { Systolic blood } \\ \text { pressure in mmHg }\end{array} & \text { Normal } & 122.1 \pm 9.6 & 0.820 \\ & \text { Poor } & 122.7 \pm 12.8 & \\ \begin{array}{l}\text { Diastolic blood } \\ \text { pressure in mmHg }\end{array} & \text { Normal } & 66.5 \pm 8.5 & 0.688 \\ & \text { Poor } & 67.3 \pm 7.8 & \\ \begin{array}{l}\text { Pulse pressure in } \\ \text { mmHg }\end{array} & \text { Normal } & 55.6 \pm 9.0 & 0.954 \\ \begin{array}{l}\text { Mean arterial blood } \\ \text { pressure in mmHg }\end{array} & \text { Normal } & 85.1 \pm 7.8 & \\ & \text { Poor } & 85.8 \pm 8.8 & 0.720\end{array}$

Heart rate variability parameters using ECG

$\begin{array}{lccc}\begin{array}{l}\text { Average heart rate } \\ \text { in beats/minute }\end{array} & \text { Normal } & 79.7 \pm 8.9 & 0.576 \\ & \text { Poor } & 80.8 \pm 8.9 & \\ \begin{array}{l}\text { NN mean in } \\ \text { milliseconds }\end{array} & \text { Normal } & 748.0 \pm 115.2 & 0.496 \\ & \text { Poor } & 731.1 \pm 109.9 & \\ \begin{array}{l}\text { SDNN in } \\ \text { milliseconds }\end{array} & \text { Normal } & 59.9 \pm 13.3 & \\ & \text { Poor } & 63.4 \pm 20.6 & 0.397 \\ \begin{array}{l}\text { RMSSD in } \\ \text { milliseconds }\end{array} & \text { Normal } & 51.2 \pm 20.2 & \\ & \text { Poor } & 57.6 \pm 27.7 & 0.262 \\ \begin{array}{l}\text { LF/HF } \\ \text { Normal }\end{array} & 1.33 \pm 0.86 & 0.542 \\ \begin{array}{l}\text { LF in normalised } \\ \text { units }\end{array} & \text { Poor } & 1.47 \pm 1.08 & \\ & \text { Normal } & 49.7 \pm 15.0 & 0.737 \\ \begin{array}{l}\text { HF in normalised } \\ \text { units }\end{array} & \text { Normal } & 44.3 \pm 12.4 & \\ & \text { Poor } & 43.2 \pm 13.4 & 0.697 \\ & & 50.9 \pm 15.9 & \end{array}$

$S D=$ standard deviation $; E C G=$ electrocardiograph; $N N$ mean = mean of the normal-to-normal heart beats; SDNN = standard deviation of the normal-to-normal heartbeats; RMSSD = square root of the mean squared differences of successive NN intervals; $L F / H F=L F / H F$ ratio; $L F=$ low frequency power; $H F=$ high frequency power.

*29 participants had normal sleep quality and 69 had poor sleep quality. U Using t-test.

sleep latency and sleep duration. The next 15 items examine how often participants experience certain symptoms such as 'cannot get to sleep in less than 30 minutes' or 'just get up to use the bathroom', etc. These 19 items produce a global sleep quality score that dichotomised the participants (those with scores $\geq 5$ have poor sleep quality and those with scores $<5$ have normal sleep quality). ${ }^{10}$ Sleep duration was estimated using the PSQI question: 'During the past month, how many hours of actual sleep did you get at night?. Based on sleep duration, students were divided into 
Table 3: Comparison of blood pressure and heart rate variability parameters between participants having normal or short sleep duration

\begin{tabular}{|c|c|c|c|}
\hline & $\begin{array}{c}\text { Sleep } \\
\text { duration } \\
\text { status }^{*}\end{array}$ & Mean \pm SD & $\begin{array}{c}P \\
\text { value }^{\dagger}\end{array}$ \\
\hline \multicolumn{4}{|c|}{ Blood pressure parameters using Finometer ${ }^{\circ}$} \\
\hline \multirow{2}{*}{$\begin{array}{l}\text { Systolic blood } \\
\text { pressure in mmHg }\end{array}$} & Short & $124.2 \pm 14.8$ & \multirow{2}{*}{0.256} \\
\hline & Normal & $121.4 \pm 9.0$ & \\
\hline \multirow{2}{*}{$\begin{array}{l}\text { Diastolic blood } \\
\text { pressure in mmHg }\end{array}$} & Short & $68.2 \pm 8.3$ & \multirow{2}{*}{0.202} \\
\hline & Normal & $66.1 \pm 7.7$ & \\
\hline \multirow{2}{*}{$\begin{array}{l}\text { Pulse pressure in } \\
\mathrm{mmHg}\end{array}$} & Short & $55.9 \pm 10.1$ & \multirow{2}{*}{0.714} \\
\hline & Normal & $55.2 \pm 8.0$ & \\
\hline \multirow{2}{*}{$\begin{array}{l}\text { Mean arterial blood } \\
\text { pressure in } \mathrm{mmHg}\end{array}$} & Short & $86.9 \pm 9.8$ & \multirow{2}{*}{0.182} \\
\hline & Normal & $84.6 \pm 7.2$ & \\
\hline \multicolumn{4}{|c|}{ Heart rate variability parameters using ECG } \\
\hline \multirow{2}{*}{$\begin{array}{l}\text { Average heart rate } \\
\text { in beats/minute }\end{array}$} & Short & $79.4 \pm 8.5$ & \multirow{2}{*}{0.318} \\
\hline & Normal & $81.2 \pm 9.1$ & \\
\hline \multirow{2}{*}{$\begin{array}{l}\text { NN mean in } \\
\text { milliseconds }\end{array}$} & Short & $746.6 \pm 108.0$ & \multirow{2}{*}{0.423} \\
\hline & Normal & $728.3 \pm 113.9$ & \\
\hline \multirow{2}{*}{$\begin{array}{l}\text { SDNN in } \\
\text { milliseconds }\end{array}$} & Short & $64.9 \pm 20.0$ & \multirow{2}{*}{0.259} \\
\hline & Normal & $60.5 \pm 17.7$ & \\
\hline \multirow{2}{*}{$\begin{array}{l}\text { RMSSD in } \\
\text { milliseconds }\end{array}$} & Short & $58.5 \pm 28.7$ & \multirow{2}{*}{0.349} \\
\hline & Normal & $53.6 \pm 23.4$ & \\
\hline \multirow[t]{2}{*}{$\mathrm{LF} / \mathrm{HF}$} & Short & $1.36 \pm 1.10$ & \multirow{2}{*}{0.595} \\
\hline & Normal & $1.47 \pm 0.96$ & \\
\hline \multirow{2}{*}{$\begin{array}{l}\text { LF in normalised } \\
\text { units }\end{array}$} & Short & $49.0 \pm 16.3$ & \multirow{2}{*}{0.402} \\
\hline & Normal & $51.7 \pm 15.0$ & \\
\hline \multirow{2}{*}{$\begin{array}{l}\text { HF in normalised } \\
\text { units }\end{array}$} & Short & $45.3 \pm 13.6$ & \multirow{2}{*}{0.255} \\
\hline & Normal & $42.2 \pm 12.7$ & \\
\hline
\end{tabular}

$S D=$ standard deviation; $E C G=$ electrocardiograph; $N N$ mean $=$ mean of the normal-to-normal heart beats; SDNN = standard deviation of the normal-to-normal heartbeats; RMSSD = square root of the mean squared differences of successive NN intervals; $L F / H F=L F / H F$ ratio; $L F=l o w$ frequency power; HF = high frequency power.

*42 participants had a short sleep duration and 56 had a normal sleep duration. ${ }^{7}$ Using t-test.

two groups: short sleep duration, consisting of those with $<6$ hours of sleep, and normal sleep duration, consisting of those with $\geq 6$ hours. ${ }^{21}$ Sleep efficiency was calculated using the ratio of total sleep time and time in bed (multiplied by 100 to yield a percentage) from the PSQI questionnaire. Based on sleep efficiency, students were categorised as having either low sleep efficiency $(<85 \%)$ or normal sleep efficiency $(\geq 85 \%) .{ }^{22}$ ESS assesses the participant's daytime sleepiness in recent times. It consists of eight items of daily routine in which participants have high chances of dozing off (e.g.
Table 4: Comparison of blood pressure and heart rate variability parameters between participants having low or normal sleep efficiency

\begin{tabular}{lccc} 
& $\begin{array}{c}\text { Sleep } \\
\text { efficiency } \\
\text { status }^{*}\end{array}$ & Mean \pm SD & $\begin{array}{c}\boldsymbol{P} \\
\text { value }^{\dagger}\end{array}$ \\
\hline \multicolumn{3}{l}{ Blood pressure parameters using Finometer } \\
$\begin{array}{l}\text { Systolic blood } \\
\text { pressure in mmHg }\end{array}$ & Low & $124.7 \pm 14.6$ & 0.187 \\
& Normal & $121.4 \pm 9.9$ & \\
$\begin{array}{l}\text { Diastolic blood } \\
\text { pressure in mmHg }\end{array}$ & Low & $68.2 \pm 8.3$ & 0.286 \\
& Normal & $66.4 \pm 7.8$ & \\
$\begin{array}{l}\text { Pulse pressure in } \\
\text { mmHg }\end{array}$ & Low & $56.4 \pm 10.6$ & 0.428 \\
$\begin{array}{l}\text { Mean arterial } \\
\text { blood pressure in } \\
\text { mmHg }\end{array}$ & Low & $87.0 \pm 9.6$ & 0.198 \\
\end{tabular}

Heart rate variability parameters using ECG

$\begin{array}{lccc}\begin{array}{l}\text { Average heart rate } \\ \text { in beats/minute }\end{array} & \text { Low } & 82.1 \pm 7.5 & 0.174 \\ & \text { Normal } & 79.5 \pm 9.5 & \\ \begin{array}{l}\text { NN mean in } \\ \text { milliseconds }\end{array} & \text { Low } & 734.1 \pm 82.0 & 0.893 \\ & \text { Normal } & 737.3 \pm 125.7 & \\ \begin{array}{l}\text { SDNN in } \\ \text { milliseconds }\end{array} & \text { Low } & 64.1 \pm 22.4 & 0.493 \\ & \text { Normal } & 61.4 \pm 16.3 & \\ \begin{array}{l}\text { RMSSD in } \\ \text { milliseconds }\end{array} & \text { Low } & 55.7 \pm 31.0 & 0.994 \\ & \text { Normal } & 55.7 \pm 22.6 & \\ \begin{array}{l}\text { LF/HF } \\ \text { Low }\end{array} & 1.62 \pm 1.2 & 0.015 \\ \begin{array}{l}\text { LF in normalised } \\ \text { units }\end{array} & \text { Lormal } & 1.31 \pm 0.82 & \\ \begin{array}{l}\text { HF in normalised } \\ \text { units }\end{array} & \text { Low } & 53.0 \pm 15.9 & 0.235 \\ & \text { Normal } & 44.2 \pm 12.5 & \\ & & 49.1 \pm 15.3 & \\ & & \end{array}$

$S D=$ standard deviation $; E G=$ electrocardiograph $; N$ mean $=$ mean of the normal-to-normal heart beats; SDNN = standard deviation of the normal-to-normal heartbeats; RMSSD = square root of the mean squared differences of successive NN intervals; $L F / H F=L F / H F$ ratio; $L F=l o w$ frequency power; $H F$ = high frequency power.

*36 participants had low sleep efficiency and 62 had normal sleep efficiency. ${ }^{\dagger} P$ value obtained from $t$-test.

sitting and reading, watching $\mathrm{TV}$, etc.). This scale uses a 4-point Likert scale ranging from 0 which is 'never doze off' to 3 which is 'high chance of dozing off.'.1

Based on the levels of sleepiness, students were categorised into 0-10 as normal daytime sleepiness, $11-12$ as mild daytime sleepiness and $\geq 13$ as moderate to severe daytime sleepiness.

Statistical Package for the Social Sciences (SPSS), Version 21 (IBM Corp., Armonk, New York, USA) was used for statistical analysis. The normality of data was tested by the Shapiro-Wilk test. Cronbach's alpha was 
0.709 and 0.741 for the PSQI and ESS questionnaires, respectively. An independent sample t-test was performed for the comparison of the two groups while one-way ANOVA with post hoc Bonferroni was employed, after being adjusted for multiple testing. Pearson's or point-biserial correlation was applied to check the relationship between variables. $P<0.05$ was regarded as statistically significant.

The participants were briefed about the study's purpose and informed consent was acquired during familiarisation sessions. Permission and ethical approval for this study were acquired from the Deanship of Scientific Research, Imam Abulrahman Bin Faisal University, Saudi Arabia (IRB-2019-01-402).

\section{Results}

A total of 98 participants were included in this study (response rate: $72.6 \%$ ). Of the 135 students that initially enrolled, 105 students completed the questionnaires; furthermore, seven participants either didn't appear on an experiment day or had insufficient ECG recordings, resulting in a final sample of 98 .

The participants had a mean age of $20.4 \pm 0.5$ years and a BMI of $22.1 \pm 2.4 \mathrm{~kg} / \mathrm{m} 2$. Mean SBP was $122.6 \pm 11.9 \mathrm{mmHg}$, DBP was $67.1 \pm 8.0 \mathrm{mmHg}$ and MABP was $85.6 \pm 8.5 \mathrm{mmHg}$. The mean of various
HRV parameters such as SDNN and LF/HF ratio was $62.4 \pm 18.8$ milliseconds and $1.43 \pm 1.02$, respectively. An average of $23.4 \pm 15.6$ minutes was taken to fall asleep; the average morning wake-up time was 6:00 $\mathrm{AM} \pm 1.24$ hours. The mean sleep duration of the participants was $5.8 \pm 1.6$ hours and their total time in bed was $6.4 \pm 2.1$ hours. The mean PSQI score was 8.2 \pm 4.0 and the mean ESS score was $8.1 \pm 5.2$ [Table 1].

A comparison of BP and HRV parameters between participants based on normal or poor sleep quality showed no statistically significant difference $(P$ $>0.05$ ) [Table 2].

A comparison of BP and HRV parameters between short or normal sleep duration revealed no statistically significant differences between the two sleep quality groups $(P>0.05)$ [Table 3 ].

A comparison of BP and HRV parameters between participants with low or normal sleep efficiency showed no statistically significant difference $(P>0.05)$ [Table 4].

A comparison of BP and HRV parameters between participants based on the ESS score using a one-way ANOVA revealed that SBP was significantly increased ( $\mathrm{f}=3.37 ; P=0.039$ ) in the moderate to severe daytime sleepiness group compared to the mild daytime sleepiness group (with Bonferroni $P=0.035$ ) [Table 5].

Table 5: Comparison of blood pressure and heart rate variability parameters between participants with daytime sleepiness based on Epworth Sleepiness Scale score

$\begin{array}{ccc}\begin{array}{c}\text { Normal daytime } \\ \text { sleepiness mean } \pm \\ \text { SD }(\mathbf{n}=66)\end{array} & \begin{array}{c}\text { Mild daytime } \\ \text { sleepiness mean } \pm \\ \text { SD }(\mathbf{n}=11)\end{array} & \begin{array}{c}\text { Moderate to severe } \\ \text { daytime sleepiness } \\ \text { mean } \pm \text { SD }(n=\end{array}\end{array} \quad$ "Pvalue

21)

Blood pressure parameters using Finometer

Systolic blood pressure in $\mathrm{mmHg}$

Diastolic blood pressure in $\mathrm{mmHg}$

Diastolic blood pressure in $\mathrm{mmHg}$

Mean arterial blood pressure in $\mathrm{mmHg}$

Heart rate variability parameters using ECG

Average heart rate in beats/minute

$\mathrm{NN}$ mean in milliseconds

SDNN in milliseconds

RMSSD in milliseconds

LF/HF ratio

LF in normalised units

HF in normalised units

$$
\begin{gathered}
122.9 \pm 10.5 \\
66.9 \pm 7.7 \\
55.9 \pm 9.0 \\
85.6 \pm 7.6 \\
80.3 \pm 9.3 \\
735.3 \pm 115.4 \\
64.8 \pm 19.6 \\
59.1 \pm 27.2 \\
1.45 \pm 1.04 \\
50.7 \pm 15.5 \\
42.8 \pm 12.6
\end{gathered}
$$

$80.6 \pm 7.3$

$80.9 \pm 9.1$

$749.1 \pm 100.4$

$60.4 \pm 21.2$

$50.4 \pm 25.5$

$1.28 \pm 1.08$

$49.2 \pm 15.6$

$47.8 \pm 13.5$
$125.8 \pm 14.6$

$69.2 \pm 9.4$

$56.5 \pm 8.8$

$88.2 \pm 10.6$

$0.039+$

0.156

0.226

0.057

$\begin{array}{cc}80.9 \pm 7.6 & 0.935 \\ 732.2 \pm 107.4 & 0.915 \\ 55.8 \pm 12.7 & 0.150 \\ 47.8 \pm 19.4 & 0.172 \\ 1.44 \pm 0.96 & 0.884 \\ 50.8 \pm 16.4 & 0.957 \\ 43.5 \pm 14.5 & 0.504\end{array}$

$S D=$ standard deviation; $E C G=$ electrocardiograph; $N N$ mean = mean of the normal-to-normal heart beats; $S D N N=$ standard deviation of the normal to-normal heartbeats; $R M S S D=$ square root of the mean squared differences of successive $N N$ intervals; $L F / H F=L F / H F$ ratio; $L F=$ low frequency power; $H F=$ high frequency power.

"Using one-way ANOVA. ${ }^{\dagger}$ Post hoc with Bonferroni. 

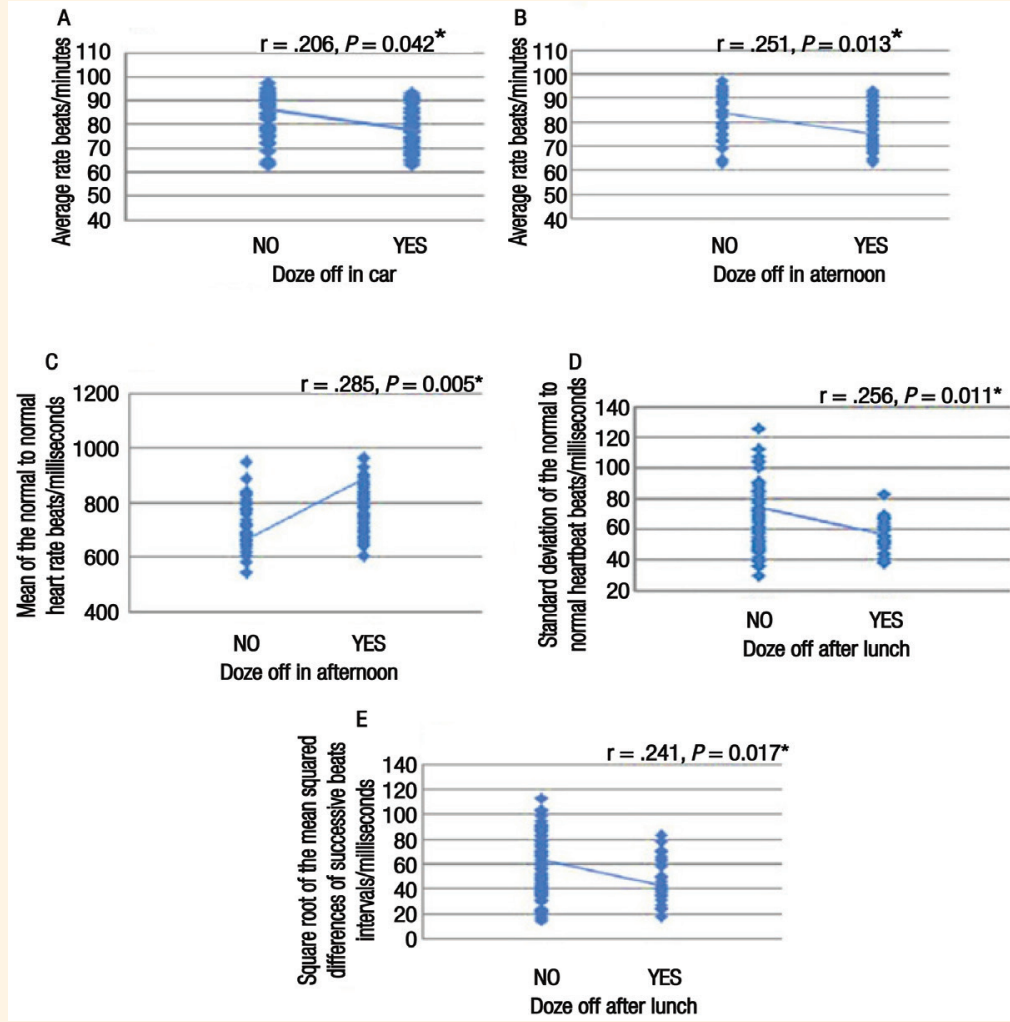

Figure 1 (A-E): Point biserial correlations of heart rate variability parameters with various doze-off situation using the Epworth Sleepiness Scale ( $\mathrm{N}=98)$.

Correlation among the PSQI parameters of sleep quality, sleep duration and sleep efficiency were not statistically significant with HRV and BP variables. However, there were point biserial correlations of HRV parameters with various dozing-off situations (measured by the ESS). Dozing off as a passenger in the car was negatively correlated with the average heart rate $(r=-0.206, P=0.042)$. Dozing off in the afternoon was also negatively correlated with the average heart rate $(\mathrm{r}=-0.251 ; P=0.013)$, but was positively correlated to the mean $\mathrm{NN}(\mathrm{r}=0.285 ; P=$ 0.005). Dozing off after lunch was negatively correlated with SDNN ( $\mathrm{r}=-0.256, P=0.011)$ and RMSSD ( $\mathrm{r}=$ $-0.241, P=0.017)$ [Figure 1].

\section{Discussion}

This study found that HRV parameters and BP measurements do not differ among young, apparently healthy female participants with various sleep patterns (sleep quality, duration and efficiency). Moreover, there is no correlation between these sleep patterns and HRV parameters. However, daytime sleepiness may influence SBP, as some of the dozing-off situations were correlated with low HRV and decreased parasympathetic control. The current study is novel in presenting the association of moderate to severe daytime sleepiness with high BP and various dozingoff situations with low HRV parameters.

Students all over the world are prone to develop disturbed sleep patterns due to demanding academic studies. A comprehensive meta-analysis of 57 studies on Chinese university students revealed a mean sleep duration of seven hours/day, a bedtime of approximately $1 \mathrm{AM}$ and an average time of 17 minutes to fall asleep. ${ }^{23}$ Another study involving American college students revealed mean PSQI scores of $6.34 \pm 4.5$, and mean ESS scores of $8.6 \pm 3.7 .{ }^{24}$ A study from KKU, Saudi Arabia, reported mean PSQI scores of $10.50 \pm 2.58$, with a sleep duration of $7.83 \pm 2.88$ and 30 minutes to fall asleep. ${ }^{7}$ All sleep parameters in that study are slightly higher compared to the current study. The underlying reason might be that the studied university has a more competitive environment compared to KKU. These study results are contrary to Dettoni et al., who reported reduced HRV in experimentally induced sleep-deprived participants. ${ }^{25}$ Similarly, Virtanen et al. observed harmful effects of acute total sleep deficit on the autonomic nervous system. ${ }^{13}$ Conflicting results observed in this study could be because of the initial response to acute sleep deprivation is sympathetically induced decreased HRV. Chronic sleep deprivation causes protective parasympathetic stimulation that buffers the sympathetic response in the absence of any 
other morbidity, as evident in these apparently healthy study participants. ${ }^{26,27}$

BP variables did not differ significantly in participants with poor sleep vs normal sleep quality. Comparable to this study's results, Kato et al. and Muenter et al. witnessed no differences in BP parameters in sleepdeprived participants. ${ }^{28,29}$ Consistent with this, Tracey postulated activation of an efferent activity of the vagus nerve to peripheral organs, particularly toward the heart, via nicotinic acetyl-choline receptors on tissue macrophages, which prevents the pro-inflammatory cytokines from inducing peripheral inflammation and possible sympathetic stimulation. ${ }^{30}$

Similar to the current study, Goldstein et al. found higher SBP in apparently healthy subjects with higher chances of daytime sleepiness and reported higher levels of anger, depression and anxiety. Their study participants were more likely to be diagnosed with hypertension in the following five years. ${ }^{31}$ Feng et al. also observed a positive correlation of excessive daytime sleepiness with BP in their patients suffering from obstructive sleep apnea. ${ }^{32}$ Similar observations have been made by Stock et al. and Taranto Montemurro et al.; notably, they witnessed a reduction in BP parameters after improvement in sleep duration. ${ }^{33,34}$

Similar to the current study's observations related to HRV changes with ESS score, Bisogni et al. didn't find any significant changes in HRV parameters concerning excessive daytime sleepiness. They concluded that excessive daytime sleepiness is not associated with sympathetic nervous system activation. $^{35}$ However, this study's results showed that the participants having higher chances of dozing off in the car as a passenger, in the afternoon and after lunch have negative correlations with the average heart rate, SDNN and RMSSD and a positive correlation with mean NN, reflecting decreased HRV and parasympathetic responses, pointing toward underlying autonomic modulation in apparently healthy participants. The mechanism by which HRV is transiently reduced following dozing off situations is not yet defined but it is likely to involve derangements in the neural activity of cardiac origin by disturbed daytime sleep patterns. One hypothesis is that sleep deprivation-induced stress can augment the sympathetic autonomic response. ${ }^{36}$

To the best of the authors' knowledge, no research so far has explored the association of HRV with daytime somnolence in healthy individuals. This study is the first to explore this association in young, apparently healthy females, principally from a student population. Despite this strength, there are certain limitations to the present study. Self-reporting of sleep patterns by the participants may involve some degree of recall errors. Actigraphy is a suitable tool for sleep parameters but due to the unavailability of actigraphy at the institute, it could not be employed. In addition, many people in the Middle East take daytime naps that were not considered when calculating the total sleep duration. Furthermore, this was a cross-sectional study, observing participants only at a single point in time. The groups were made based on the cutoff levels of sleep pattern variables and without the power. The unequal number of study participants in the groups may affect type 1 error rates. The narrow age range of the study's population was also an important limitation. Another limitation is that the probable impact of sleep patterns on the autonomic nervous system in young individuals may be mistaken by the apparently healthy nervous system. This study's participants were only female and recruited from a single university which may limit the generalisability of the results. In the future, studies with a large cohort and from different student population groups of both genders should be planned.

\section{Conclusion}

The current study has shown that BP and HRV parameters do not differ among young, apparently healthy female students with various sleep patterns (sleep quality, duration and efficiency). Moreover, there is no relationship between sleep patterns and HRV parameters. Moderate to severe daytime sleepiness increases SBP and various dozing off situations may have a negative correlation with HRV parameters, directed towards an overall decrease in the HRV (average heart rate, SDNN) and a decrease in the parasympathetic autonomic control (RMSSD). Daytime somnolence may be a useful tool to detect early HRV changes that were otherwise masked in healthy subjects. Early detection of autonomic dysfunction may be beneficial in identifying future cardiovascular morbidities in a healthy generation.

\section{CONFLICT OF INTEREST}

The authors declare no conflicts of interest.

\section{FUNDING}

No funding was received for this study.

\section{AUTHORS' CONTRIBUTION}

FM and RL conceptualized the idea and collected the data. Acquisition, interpretation and analysis of the data were done by FM, RL, AL and RB. FM, RL, $\mathrm{AL}$ and $\mathrm{RB}$ drafted and revised the manuscript. All authors approved the final version of the manuscript. 


\section{References}

1. Tufik S, Andersen ML, Bittencourt LR, Mello MT. Paradoxical sleep deprivation: Neurochemical, hormonal and behavioral alterations. Evidence from 30 years of research. An Acad Bras Cienc 2009; 81:521-38. https://doi.org/10.1590/S000137652009000300016 .

2. Tobaldini E, Costantino G, Solbiati M, Cogliati C, Kara T, Nobili L, et al. Sleep, sleep deprivation, autonomic nervous system and cardiovascular diseases. Neurosci Biobehav Rev 2017; 74:321-9. https://doi.org/10.1016/j.neubiorev.2016.07.004.

3. Zhu G, Catt M, Cassidy S, Birch-Machin M, Trenell M, Hiden H, et al. Objective sleep assessment in $>80,000$ UK mid-life adults: Associations with sociodemographic characteristics, physical activity and caffeine. PLoS One 2019; 14:e0226220. https://doi. org/10.1371/journal.pone.0226220.

4. Baldwin CM, Kapur VK, Holberg CJ, Rosen C, Nieto FJ; Sleep Heart Health Study Group. Associations between gender and measures of daytime somnolence in the Sleep Heart Health Study. Sleep 2004; 27:305-11. https://doi.org/10.1093/sleep/27.2.305.

5. Nowakowski S, Meers J, Heimbach E. Sleep and women's health. Sleep Med Res 2013; 4:1-22. https://doi.org/10.17241/smr.2013.4.1.1.

6. Felix VA, Campsen NA, White A, Buboltz WC. College students' prevalence of sleep hygiene awareness and practices. Adv Soc Sci 2017; 4. https://doi.org/10.14738/assrj.44.2767.

7. Siddiqui AF, Al-Musa H, Al-Amri H, Al-Qahtani A, Al-Shahrani M, Al-Qahtani M. Sleep patterns and predictors of poor sleep quality among medical students in King Khalid University, Saudi Arabia. Malays J Med Sci 2016; 23:94-102. https://doi.org/10.21315/ mjms2016.23.6.10.

8. Sweileh WM, Ali I, Sawalha AF, Abu-Tah AS, Zyoud SH, Al-Jabi SW. Gender differences in sleep habits and sleeprelated problems in Arab Palestinian university students. Int J Disabil Hum Dev 2012; 11:289-93. https://doi.org/10.1515/ ijdhd-2012-0041.

9. Tsai LL, Li SP. Sleep patterns in college students: Gender and grade differences. J Psychosom Res 2004; 56:231-7. https://doi. org/10.1016/S0022-3999(03)00507-5

10. Buysse DJ, Reynolds CF, Monk TH, Berman SR, Kupfer DJ. The Pittsburgh sleep quality index: A new instrument for psychiatric practice and research. Psychiatry Res 1989; 28:193-213. https:// doi.org/10.1016/0165-1781(89)90047-4.

11. Janssen KC, Phillipson S, O'Connor J, Johns MW. Validation of the Epworth Sleepiness Scale for children and adolescents using Rasch analysis. Sleep Med 2017; 33:30-5. https://doi. org/10.1016/j.sleep.2017.01.014.

12. Alotaibi AD, Alosaimi FM, Alajlan AA, Bin Abdulrahman KA. The relationship between sleep quality, stress, and academic performance among medical students. J Family Community Med 2020; 27:23-8. https://doi.org/10.4103/jfcm.JFCM_132_19.

13. Virtanen I, Kalleinen N, Urrila AS, Leppänen C, Polo-Kantola P. Cardiac autonomic changes after 40 hours of total sleep deprivation in women. Sleep Med 2015; 16:250-7. https://doi.org/10.10 16/j.sleep.2014.10.012

14. Vaara J, Kyröläinen H, Koivu M, Tulppo M, Finni T. The effect of 60-h sleep deprivation on cardiovascular regulation and body temperature. Eur J Appl Physiol 2009; 105:439-44. https://doi. org/10.1007/s00421-008-0921-5.

15. Taralov ZZ, Terziyski KV, Kostianev SS. Heart rate variability as a method for assessment of the autonomic nervous system and the adaptations to different physiological and pathological conditions. Folia Med (Plovdiv) 2015; 57:173-80. https://doi. org/10.1515/folmed-2015-0036

16. Bilchick KC, Berger RD. Heart rate variability. J Cardiovasc Electrophysiol 2006; 17:691-4. https://doi.org/10.1111/j.15408167.2006.00501.x
17. Fatima Y, Doi SA, Mamun AA. Sleep quality and obesity in young subjects: A meta-analysis. Obes Rev 2016; 17:1154-66. https://doi.org/10.1111/obr.12444

18. ECG/EKG signals. From: https://www.adinstruments.com/sig nal/ecg Accessed: Sep 2020.

19. Guelen, I, Westerhof BE, Van Der Sar GL, Van Montfrans GA, Kiemeneij F, Wesseling KH, et al. Finometer, finger pressure measurements with the possibility to reconstruct brachial pressure. Blood Press Monit 2003; 8:27-30. https://doi.org/10.1097/001260 97-200302000-00006.

20. Radespiel-Tröger M, Rauh R, Mahlke C, Gottschalk T, MückWeymann M. Agreement of two different methods for measurement of heart rate variability. Clin Auton Res 2003; 13:99-102. https://doi.org/10.1007/s10286-003-0085-7.

21. Chen HC, Hsu NW, Chou P. The association between extreme sleep duration and cardiac autonomic control in communitydwelling older adults: The Yilan Study, Taiwan. J Gerontol A Biol Sci Med Sci 2017; 72:929-36. https://doi.org/10.1093/gerona/ glx045.

22. Matthews EE, Schmiege SJ, Cook PF, Berger AM, Aloia MS. Adherence to cognitive behavioral therapy for insomnia (CBTI) among women following primary breast cancer treatment: A pilot study. Behav Sleep Med 2012; 10:217-9. https://doi.org/1 $0.1080 / 15402002.2012 .666220$.

23. Li L, Wang YY, Wang SB, Li L, Lu L, Ng CH, et al. Sleep duration and sleep patterns in Chinese university students: A comprehensive meta-analysis. J Clin Sleep Med 2017; 13:1153-62. https://doi.org/10.5664/jcsm.6760.

24. Dietch JR, Taylor DJ, Sethi K, Kelly K, Bramoweth AD, Roane BM. Psychometric evaluation of the PSQI in U.S. college students. J Clin Sleep Med 2016; 12:1121-9. https://doi.org/10.5664/ jcsm.6050

25. Dettoni JL, Consolim-Colombo FM, Drager LF, Rubira MC, Souza SB, Irigoyen MC, et al. Cardiovascular effects of partial sleep deprivation in healthy volunteers. J Appl Physiol (1985) 2012; 113:232-6. https://doi.org/10.1152/japplphysiol.01604.2011.

26. Pagani M, Pizzinelli P, Traon AP, Ferreri C, Beltrami S, Bareille MP, et al. Hemodynamic, autonomic and baroreflex changes after one night sleep deprivation in healthy volunteers. Auton Neurosci 2009; 145:76-80. https://doi.org/10.1016/j.autneu.2008.10.009.

27. Quintana DS, Elvsåshagen T, Zak N, Norbom LB, Pedersen PØ, Quraishi SH, et al. Diurnal variation and twenty-four hour sleep deprivation do not alter supine heart rate variability in healthy male young adults. PLoS One 2017; 12:e0170921. https://doi. org/10.1371/journal.pone.0170921.

28. Kato M, Phillips BG, Sigurdsson G, Narkiewicz K, Pesek CA, Somers VK. Effects of sleep deprivation on neural circulatory control. Hypertension 2000; 35:1173-5. https://doi.org/10.116 1/01.hyp.35.5.1173.

29. Muenter NK, Watenpaugh DE, Wasmund WL, Wasmund SL, Maxwell SA, Smith ML. Effect of sleep restriction on orthostatic cardiovascular control in humans. J Appl Physiol (1985) 2000; 88:966-72. https://doi.org/10.1152/jappl.2000.88.3.966.

30. Tracey KJ. The inflammatory reflex. Nature 2002; 420:853-9. https://doi.org/10.1038/nature01321.

31. Goldstein IB, Ancoli-Israel S, Shapiro D. Relationship between daytime sleepiness and blood pressure in healthy older adults. Am J Hypertens 2004; 17:787-92. https://doi.org/10.1016/j.amjhy per.2004.05.009.

32. Feng J, He QY, Zhang XL, Chen BY; Sleep Breath Disorder Group, Society of Respiratory Medicine. Epworth Sleepiness Scale may be an indicator of blood pressure profile and prevalence of coronary artery disease and cerebrovascular disease in patients with obstructive sleep apnea. Sleep Breath 2012; 16:31-40. https://doi.org/10.1007/s11325-011-0481-5. 
33. Stock AA, Lee S, Nahmod NG, Chang AM. Effects of sleep extension on sleep duration, sleepiness, and blood pressure in college students. Sleep Health 2020; 6:32-9. https://doi.org/10.1016/j. sleh.2019.10.003.

34. Taranto Montemurro LT, Floras JS, Picton P, Kasai T, Alshaer H, Gabriel JM, et al. Relationship of heart rate variability to sleepiness in patients with obstructive sleep apnea with and without heart failure. J Clin Sleep Med 2014; 10:271-6. https://doi.org/10.566 4/jcsm.3526.
35. Bisogni V, Pengo MF, Drakatos P, Maiolino G, Kent B, Rossitto G, et al. Excessive daytime sleepiness does not correlate with sympathetic nervous system activation and arterial stiffening in patients with mild-to-moderate obstructive sleep apnoea: A proof-ofprinciple study. Int J Cardiol 2017; 236:458-61. https://doi.org/1 0.1016/j.ijcard.2017.01.149.

36. Lombardi C, Parati G, Cortelli P, Provini F, Vetrugno R, Plazzi G, et al. Daytime sleepiness and neural cardiac modulation in sleep-related breathing disorders. J Sleep Res 2008; 17:263-70. https://doi.org/10.1111/j.1365-2869.2008.00659.x. 